\title{
Metabolic and energetics characterization and gender comparison in prepubertal karate practitioners
}

\author{
António VENCESBRIT0*1,2,3,4, Mário A. RODRIGUES-FERREIRA1,2,3, Vitor MILHEIR01,2,3, \\ Marco BRANC0 $1,3,4,5$, Cristiana MERCÊ $\hat{1}^{1,2,3}$, Ana Paula SEABRA ${ }^{1,2,3}$, \& David CATELA $1,2,3$ \\ ${ }^{1}$ Sports Sciences School of Rio Maior - Polytechnic Institute of Santarém (Portugal) \\ ${ }^{2}$ Quality Life Research Center (CIEQV) (Portugal) \\ ${ }^{3}$ Research Unite of Polytechnic Institute of Santarém (UIIPS) (Portugal) \\ ${ }^{4}$ International Martial Arts and Combat Sports Scientific Society-IMACSSS (Poland) \\ ${ }^{5}$ Biomechanics and Functional Morphology Laboratory, Interdisciplinary Centre for the Study of \\ Human Performance (CIPER), Faculty of Human Kinetics, University of Lisbon (Portugal)
}

\begin{abstract}
The number of children practicing karate is constantly increasing. It is necessary to provide correct information to the karate masters/coaches about this specific population, so they can properly develop karate training processes without causing any harm to practitioners but, on the contrary, contribute to the harmonious development of children and youths. This study was carried out with twenty-one prepubertal karate practitioners, male and female. They were analyzed on their maturational development, metabolic and energetic behavior in an incremental test until exhaustion. Only the energetic variables presented significant differences between gender, so it seems that the karate practice has a similar metabolic impact in the development of the prepubertal karate practitioners of both genders.
\end{abstract}

Keywords: Martial arts; combat sports; children; metabolism; energetics; karate.

\section{Introduction}

Today it's normal to see young children practice karate with high intensity and competing in tournaments. So it is necessary to understand the effects of karate practice in young children, namely in what is concerned to their metabolic and energetic responses and adaptations and specialization to the karate practice. We must understand that children are not adults in miniature, and, as such, their physiological and metabolic responses to effort vary according to age and gender, as reported in several studies performed with population with and without developing sport practice (Eliakim et al., 2019; Malik, Williams, Weston, \& Barker, 2019). However, studies about this topic are quite scarce in the field of karate, especially in the evaluation of children, which makes this study relevant to the karate coaches and to all karate practitioners, in what it is concerned to the optimization of the training methodologies according with the correct level of effort required, the practitioners ages and genders, or the metabolic and energetics specific capacities.

\section{Objectives}

The main purpose of this study was to characterize the metabolic and energetics responses during effort in prepubertal children with ages between 8 and 11 years old that practice karate. The second aim was to verify the existence of differences between genders in the metabolic and energetics variables analyzed.

\footnotetext{
*Email: abrito@esdrm.ipsantarem.pt
} 


\section{Methodology}

The sample was recruited in Karate clubs and associations affiliated to the Portuguese Karate Federation (FNK-P). Before the data collection, the study was explained to the parents and to the children and informed consent was obtained from them. The study was approved by the Ethics Committee of the Research Unit of the Polytechnic Institute of Santarém.

Twenty-one prepubertal karate practitioners participated in the study, fifteen males and six females (age: $\mathrm{M}-9 \mathrm{yr} . \pm 1, \mathrm{~F}-9$ yr. \pm 2 ; height: $\mathrm{M}-135 \mathrm{~cm} \pm 9,2, \mathrm{~F}-136 \mathrm{~cm} \pm 10,7$; weight: $\mathrm{M}-30.2$ $\mathrm{kg} \pm$ 5.8, F - $31.3 \mathrm{~kg} \pm$ 5.3; Tanner's stage: $\mathrm{M}-2$, F - 2; IMC: $\mathrm{M}-16.2, \mathrm{~F}-16,7$; karate level: $\mathrm{M}-7$ o to $5^{\circ} \mathrm{kyu}, \mathrm{F}-7^{\circ}$ to $4^{\mathrm{o}} \mathrm{kyu}$; hours of karate weekly training: $\mathrm{M}-4 \mathrm{~h} \pm 1, \mathrm{~F}-3 \mathrm{~h} \pm 1$; hours of school physical education: M - $2 \mathrm{~h}, \mathrm{~F}-2 \mathrm{~h}$ ).

Protocols proposed by the International Society for the Advancement of Kinanthropometry (ISAK), and the assessment of biological maturation through self-rating, (Malina \& Beunen, 2008; Tanner, 1962) were used to assess the children's maturational and biological state.

Regarding metabolic indicators in effort, we used an incremental treadmill protocol, modified Balke test (Heyward, 2006), applied until exhaustion (volitional fatigue or maximum criterion was achieved), on the Technogym Runrace Treadmill HC1200 (Italy), with the use of COSMED K4 b2 portable metabolic measurement system, and acknowledge software to collect and analyze data on respiratory frequency (RF), carbon dioxide production $\left(\mathrm{VCO}_{2}\right)$, oxygen uptake $\left(\mathrm{VO}_{2}\right)$, heart rate $(\mathrm{HR})$, in the total exercise time. The final three minutes of exercise were considered the active recovery after exhaustion. It was also analyzed the energy expenditure (EEm) and the metabolic equivalents (METS) in the exercise.

To examine the study data, it was first performed a simple descriptive statistical analysis (mean and stander deviation values), then, after verified the normality and homogeneity of the sample, a comparison was made between genders with the $U$ Mann-Whitney test with the Statistical Package for Social Sciences, version 20 (SPSS Inc, USA). The significance level was set at $p<0.05$ for all comparisons.

\section{Results}

Considering the mean and standard-deviation values, in the male (M) karate children the total exercise time was of 12 minutes, and in the female (F) was of 11.45 minutes, wherein the last three minutes of recovery that occurs after exhaustion, are included in the total time. During the exercise the RF was of 42 breaths min $^{-1} \pm 13$ in both genders, but the HR was of $141 \mathrm{bpm} \pm 30$ in M and $140 \mathrm{bpm} \pm 28 \mathrm{in} \mathrm{F}$. In the recovery the HR decrease $69 \mathrm{bpm} \pm 14$ in $\mathrm{M}$ and $56 \mathrm{bpm} \pm 20 \mathrm{in} \mathrm{F}$.

Regarding to the gas analysis, the absolute $\mathrm{VCO}_{2}$ production was $746 \mathrm{ml} \mathrm{min}^{-1} \pm 377$ and the $\mathrm{VO}_{2}$ uptake was $786.9 \mathrm{ml} \mathrm{min}^{-1} \pm 355$ corresponding to a relative value of $27.2 \mathrm{ml} \mathrm{kg}^{-1} \mathrm{~min}^{-1} \pm 11.7 \mathrm{in}$ male; in female $\mathrm{VCO}_{2}$ was $777 \mathrm{ml} \mathrm{min}{ }^{-1} \pm 417$, the $\mathrm{VO}_{2}$ uptake was $779.4 \mathrm{ml} \mathrm{min}^{-1} \pm 335$ corresponding to a relative value of $24.9 \mathrm{ml} \mathrm{kg}^{-1} \mathrm{~min}^{-1} \pm 10.2$.

In the male group, on three minutes of recovery, the absolute $\mathrm{VCO}_{2}$ production was $822.6 \mathrm{ml}$ $\mathrm{min}^{-1} \pm 177.6$ with a $\mathrm{VO}_{2}$ uptake of $751.1 \mathrm{ml} \mathrm{min}^{-1} \pm 156.5$ corresponding to a relative value of 25.4 $\mathrm{ml} \mathrm{kg}-1 \mathrm{~min}^{-1} \pm 4.03$, and in female the $\mathrm{VCO}_{2}$ was $861.8 \mathrm{ml} \mathrm{min}^{-1} \pm 239.4$, the $\mathrm{VO}_{2}$ uptake was $748 \mathrm{ml}$ $\mathrm{min}^{-1} \pm 166.84$ corresponding to a relative value of $24.05 \mathrm{ml} \mathrm{kg}^{-1} \mathrm{~min}^{-1} \pm 4.1$. The energy cost of the test in male, presented energy expenditure of $1454.4 \mathrm{Kcal} \mathrm{min}^{-1} \pm 116.4$ and $7.7 \mathrm{METS} \pm 3.4$, while the female has $884.8 \mathrm{Kcal} \mathrm{min}^{-1} \pm 137.7$ and $8.6 \mathrm{METS} \pm 3.8$ during all the exercise time.

Gender comparison showed significant differences in EEm $(p=0.044)$ and METS $(p=$ 0.002). The variable relative $\mathrm{VO}_{2}(p=0.066)$ showed a tendency to statistical difference.

\section{Discussion}

Although children participating in this study presented similar anthropometrical and maturational characteristics, and in cardiorespiratory variables, it seems to exist a different behavior in the energetic field when they perform a maximal physical effort, as usually happens in karate practice. Male children supported a little more time of maximal effort than female children 
before reaching exhaustion, however, this did not have significant consequences in the RF or in the HR during the exercise fulfilment or in the recovery time, even though the male karate children tended to recover better they HR, returning faster to an initial HR state than the females.

Despite the inexistence of significant differences on $\mathrm{VCO}_{2}$ and $\mathrm{VO}_{2}$ variables, it seems that the male karate group tended to have more efficiency in the gas exchanges, and this may be associated with a better adapted metabolism to the high intensity effort, induced by the karate practice. This is reflected by the higher values of $\mathrm{VO}_{2}$ and the lower production of $\mathrm{VCO}_{2}$ in male karate children. However, this study was limited to just one karate children sample, so it is not possible, at this moment, to state that these results would not be different in children who do not practice karate, or in those who practice other sports than karate.

\section{Conclusion}

The prepubertal karate practitioners reached to exhaustion in a high intensity exercise after $12 \mathrm{~min}$, with relative $\mathrm{VO}_{2}$ intakes between 25 and $27 \mathrm{ml} \mathrm{kg}^{-1} \mathrm{~min}^{-1}$, and an energetic expenditure between 884 and $1454 \mathrm{Kcal} \mathrm{min}^{-1}$. In general, there were no significant differences between genders on the assessed metabolic or maturational characteristics, although differences were found in energy expenditure and the metabolic equivalents during exercise.

\section{Acknowledgements}

The authors are grateful for the availability of athletes and coaches from: Associação AMICALE Karate; AKDS Clube Atlético do Montijo; AKWK - Associação de Karaté-Do Wado-Kai.

\section{References}

Heyward, V. (2006). Advanced Fitness Assessment and Exercise Prescription (6 ed.). Champaign: Human Kinetics

Malina, R. M., \& Beunen, G. (2008). Growth and Maturation: Methods of Monitoring. In H. Hebestreit \& O. Bar-Or (Eds.), The Young Athlete (pp. 430-42). Oxford: Blackwell Publishing.

Malik, A., Williams, C., Weston, K., \& Barker, A. (2019). Perceptual and Cardiorespiratory Responses to High-Intensity Interval Exercise in Adolescents: Does Work Intensity Matter? Journal of Sports Science \& Medecine, 18, 1-12.

Tanner JM (1962). Growth at adolescence (2 ed.). Oxford: Blackwell.

Eliakim, A., Falk, B., Armstrong, N., Baptista, F., Behm, D. G., Dror, N., .. R Rowlands, A. V. (2019). Expert`s choice: 2018`s most exciting research in the field of pediatric exercise science. Pediatric Exercise Science, 31(1), 1-27. doi: 10.1123/pes.2019-0010 